\title{
Gestão Ambiental em Instituição de Ensino Superior na Visão de seus Dirigentes
}

\author{
Environmental Management in an Institution of Higher Learning from the \\ Viewpoint of its Directors \\ Marines Lúcia Boff \\ Mestre em Ciências Contábeis \\ Ieda Margarete Oro \\ Mestre em Ciências Contábeis \\ Ilse Maria Beuren \\ Doutora em Contabilidade e Controadoria
}

\section{Resumo}

O trabalho objetiva descrever a gestão ambiental em Instituição de Ensino Superior comunitária, na visão de seus dirigentes. Partiu-se da premissa de que a gestão ambiental não se restringe mais a um determinado grupo de empresas que se utilizam dos recursos naturais para o desenvolvimento de suas atividades, mas estende-se à qualquer tipo de organização e comunidade em geral. Em vista disso, realizou-se um estudo exploratório, por meio de estudo de caso em uma Instituição de Ensino Superior (IES) filantrópica e comunitária, com abordagem qualitativa dos dados. Os resultados da pesquisa mostram que, assumir ou não essa responsabilidade depende das crenças e valores dos principais dirigentes da IES, visto que são eles os tomadores das decisões. Seus princípios e práticas com relação ao meio ambiente são fundamentais no tratamento dos impactos ambientais causados pela IES. Conclui-se que às IES, principalmente por serem provedoras e disseminadoras de conhecimento, recai também a responsabilidade pela proteção e qualidade do meio ambiente onde estão inseridas.

Palavras-chave: Gestão ambiental. Responsabilidade social. Instituição de Ensino Superior.

\begin{abstract}
The objective of the present work is to describe environmental management in a community Institution of Higher Learning from the viewpoint of its directors. It starts with the premise that environmental management is no longer restricted to a determined group of companies that use natural resources for the development of their activities, but extends to any type of organization and community in general. In light of this, an exploratory study was made, by means of a case study of a philanthropic and community-based Institution of Higher Learning (IES), using a qualitative approach with data. Research results show that assuming or not assuming responsibility depends on the beliefs and values of the principal directors of the IES, since they are the decision makers. Their principles and practices in relation to the environment are fundamental to the treatment of impacts to the environment caused by the IES. The study concluded that mainly because of their being providers and disseminators of knowledge, responsibility also falls to them for the protection and quality of the environment where they are inserted.
\end{abstract}

Key words: Environmental management. Social responsibility. Institution of Higher Learning. 


\section{Introdução}

As Instituições de Ensino Superior (IES), tidas como provedoras e disseminadoras de conhecimento, se auto condicionam a serem instituições éticas e responsáveis pela melhora e proteção da qualidade do meio ambiente, atuando de forma ecologicamente correta. Esse auto condicionamento das IES é decorrente da ampliação da consciência com relação ao meio ambiente, da sociedade em geral e das pessoas que buscam conhecimentos nas universidades em especial. Elas induzem também as demais organizações a um novo posicionamento sobre gestão ambiental no ambiente em que estão inseridas.

Nesse sentido, as IES necessitam desenvolver e implementar estratégias voltadas à gestão ambiental, que envolvam os esforços de todas as pessoas inseridas em sua hierarquia. Tal deve trnscorrer no sentido de evitar, controlar e/ou eliminar todo e qualquer tipo de impacto ambiental, causado direta ou indiretamente, voluntariamente ou não, em proporções pequenas, médias ou grandes, pela instituição.

Entretanto, o delineamento das estratégias de gestão ambiental depende das crenças e valores dos principais dirigentes da IES, visto que são estes os tomadores das decisões inerentes aos assuntos de interesse da instituição. Sua filosofia e sua visão com relação ao meio ambiente são fundamentais na condução da gestão ambiental das IES sob sua responsabilidade.

Diante do exposto busca-se responder a seguinte questão-problema: Como se configura a gestão ambiental em uma Instituição de Ensino Superior comunitária, na visão de seus dirigentes? Para responder à pergunta da pesquisa levantada estabeleceu-se como objetivo geral para o trabalho descrever a gestão ambiental em Instituição de Ensino Superior comunitária, na visão de seus dirigentes. Como objetivos específicos têm-se: a) conhecer a visão dos dirigentes de uma IES comunitária sobre gestão ambiental; b)identificar práticas e procedimentos de gestão ambiental adotados na IES; c) demonstrar benefícios sociais e estratégicos da gestão ambiental na IES comunitária pesquisada.

Justifica-se este estudo, pois a gestão ambiental não se restringe mais a um determinado grupo de empresas que se utilizam dos recursos naturais para o desenvolvimento de suas atividades. $\mathrm{O}$ conhecimento sobre as questões ambientais se faz presente e necessário em todos os espaços da sociedade, visto a importância da manutenção e conservação dos recursos naturais, essenciais para toda humanidade.

O artigo está estruturado em cinco partes além dessa introdução. Inicia com uma abordagem teórica sobre responsabilidade social. Segue com uma incursão em gestão ambiental, com ênfase em princípios de um sistema de gestão ambiental e benefícios da gestão ambiental em instituição de ensino superior. Na seqüência descreve os procedimentos metodológicos adotados na pesquisa. Em seguida apresenta os dados e resultados da pesquisa. Por fim, faz considerações finais ao estdo realizado.

\section{Responsabilidade social}

Pereira (1999, p.77) menciona que, "entre os objetivos mais gerais de uma empresa, destacam-se os sociais e econômicos, que devem ser conciliados, por serem fundamentais para que a empresa mantenha equilíbrio em sua estrutura interna e em relação a seu ambiente". Na busca pela concretização dos objetivos pretendidos, toda atividade empresarial, com ou sem fins lucrativos, provoca, voluntária ou involuntariamente, danos ao meio ambiente no decorrer de suas atividades. Nesse sentido, é imprescindível que ela tenha um sistema de gestão ambiental (SGA).

A responsabilidade é uma das maneiras de expressar os princípios éticos e morais da pessoa, na medida em que cumpre suas obrigações para com os outros e respeita os direitos destes, para só então exigir que os seus próprios direitos sejam respeitados. As práticas empresariais éticas e morais estão intimamente relacionadas com a imagem da organização. 
Para Rosini e Palmisano (2003, p.143), a ética "está intimamente comprometida com o respeito, confiabilidade e segurança, fatores que constróem ou destróem a imagem das organizações.

A convocação da sociedade para as empresas assumir sua responsabilidade social requer que estas repensem seu papel no mercado competitivo. A sociedade, ao interagir com as organizações, requer destas uma relação ética e transparente, por meio de atitudes responsáveis, tanto no que concerne ao seu ambiente interno quanto externo. Nesse sentido, Rehfeldt (2006) cita que quanto mais complexa for a sociedade em que o indivíduo vive, mais variadas e diversificadas serão as situações que exigem respostas responsáveis, ou seja, que levem em consideração a existência do outro com seus direitos e suas obrigações.

De acordo com o Instituto Ethos (www.ethos.ogr.br), ao assumir a responsabilidade social na condução de suas atividades, a organização se torna parceira e co-responsável pelo desenvolvimento social. Tem a capacidade de ouvir os interesses das diferentes partes (empregados, comunidade, governo, entre outros) e, incorporá-los ao planejamento de suas atividades, buscando atender às demandas de todos.

Para Oliveira (2002, p. 205), a responsabilidade social "é o objetivo social da empresa somado à sua atuação econômica. É a inserção da organização na sociedade como agente e não somente econômico". Rosini e Palmisano (2003) salientam que, a responsabilidade social trata da conscientização da parcela de responsabilidade que cabe a cada setor da sociedade e a cada indivíduo desta, em relação à própria sociedade, sendo que esta conscientização complementa a ética, mental e efetivamente, uma vez que esses conceitos só têm valor à medida que se transformam em ações.

Diversas iniciativas já estão sendo empreendidas pelos mais variados tipos de organizações e órgãos, sejam eles reguladores, financiadores ou usuários dos recursos sob sua responsabilidade e do seu entorno. Inclusive com preocupações sobre a evidenciação de suas ações, conforme citam Calixto, Barbosa e Lima (2007, p. 86-87), que "muitas informações qualitativas são divulgadas voluntariamente pelas empresas brasileiras através do relatórios conhecido como Balanço Social, que agrega valores sociais, ambientais e humanos das atividades empresariais".

Observa-se, portanto, que independente do ramo de atividade, as organizações devem considerar, além das questões econômicas e financeiras, as questões sociais, ambientais e humanos, tendo como foco todos os segmentos da sociedade com as quais se relacionam. Esta postura implica, entre outras providências, implantar um sistema de gestão ambiental.

\section{Gestão ambiental}

Ferreira (2003, p. 30) alerta que "a gestão ambiental pode começar, muitas vezes, pela iniciativa individual de um funcionário ou de um grupo deles. Pode ser a partir de uma coleta seletiva de lixo com a separação do papel, latas e vidros". Em muitas situações nem se percebe, mas se está gerenciando o meio ambiente ou praticando a gestão ambiental: quando se reutiliza um recipiente; se utiliza as sacolas plásticas do mercado para depósito de lixos; se reutiliza papel para rascunho; se vai de carona ao invés de ir de condução própria.

Tinoco e Kraemer (2004, p.109) citam que "gestão ambiental é o sistema que inclui a estrutura organizacional, atividades de planejamento, responsabilidades, práticas, procedimentos, processos e recursos para desenvolver, implementar, atingir, analisar criticamente e manter a política ambiental".

Segundo ISO (1998), o Sistema de Gestão Ambiental (SGA) é um elemento do sistema de gestão global da organização, que compreende "a estrutura oranizacional, atividades de planejamento, responsavilidades, práticas, procedimentos, processos e recursos para desenvolver, implementr, atingir, analisar criticamente e manter a política ambiental". 
Sistema de gestão ambiental (SGA) pode ser definido, conforme Tinoco e Kraemer (2004), como um conjunto de procedimentos e métodos auxiliares da administração de uma organização, visando obter o melhor relacionamento com o meio ambiente, por meio do planejamento de suas atividades, procurando eliminar ou minimizar os impactos ambientais, por ações de prevenção ou redução dos impactos.

A principal finalidade de um sistema de gestão ambiental (SGA) é auxiliar os administradores com informações relativas à gestão ambiental, oferecendo-lhes procedimentos e métodos capazes de eliminar ou reduzir os impactos negativos causados pela organização de forma involuntária. Segundo Leonardo (2006, p. 91), "a implantação de um sistema de gestão ambiental facilita a identificação dos problemas ambientais em que a empresa está envolvida, bem como possíveis soluções para eliminá-los ou equacioná-los".

Depreende-se do exposto que um sistema de gestão ambiental poderá ser implantado para reduzir os poluentes que estão causando impactos negativos ao meio ambiente, depois que estes já foram gerados por terceiros, ou para evitar que tais poluentes sejam gerados posteriormente.

\subsection{Princípios de um sistema de gestão ambiental}

Segundo Tinoco e Kraemer (2004), para estabelecer um SGA em uma instituição, a organização deverá basear-se em alguns princípios que darão suporte às etapas, a saber:

a) princípio da política do ambiente - é o primeiro passo a ser dado na implementação de um SGA. É a posição adotada pela instituição no sentido de comprometimento com as questões ambientais;

b) princípio do planejamento - a instituição deve identificar os aspectos ambientais (poluentes) que controla e sobre os quais exerce influência, e avaliar seu impacto no meio ambiente, devendo igualmente garantir que esses impactos sejam considerados no estabelecimento de sua política ambiental;

c) princípio da implementação - nesse momento, as regras e responsabilidades devem estar definidas, documentadas e comunicadas a todos, de forma a garantir sua aplicação.

Política ambiental é definida pela Associação Brasileira de Normas Técnicas (ABNT) (1996) como "a declaração da organização expondo suas intenções e princípios em relação ao seu desempenho ambiental global, que prevê uma estrutura de ação e definição de seus objetivos e metas ambientais".

De acordo com Tinoco e Kraemer (2004), assim como em qualquer instituição ou departamento desta, onde há necessidade de designar pessoas com responsabilidades, na implantação de um SGA, a administração é responsável para providenciar:

a) os meios humanos, tecnológicos, financeiros e de controle;

b) formação a seus colaboradores, conscientizando-os da importância da política do ambiente, da relevância do impacto ambiental de suas atividades, da responsabilidade em implementar um SGA e das conseqüencias ambientais de trabalhar em conformidade com procedimentos específicos;

c) estabelecer e manter procedimentos para a comunicação interna entre os vários níveis hierárquicos, assim como receber e responder às partes externas.

Desta forma, os responsáveis pela implantação do SGA em uma instituição ou entidade devem possuir, além dos recursos materiais necessários, conhecimento da legislação ambiental e inserção nos diversos níveis da hierarquia corporativa para articular tanto no âmbito interno como externo. 


\subsection{Benefícios da gestão ambiental em instituição de ensino superior}

$\mathrm{O}$ estabelecimento da gestão ambiental numa IES tende a criar benefícios para o meio ambiente e para a instituição. O meio ambiente ganha quando existe uma racionalidade no uso dos recursos naturais, como por exemplo, o uso racional da água. Também ganha, quando deixa de receber poluentes oriundos das atividades operacionais da instituição, como esgoto, recipientes, papel, plástico, vidro, etc.

Para a IES, a gestão ambiental lhe beneficiará com a economia de custos, pela redução do consumo de água, energia elétrica, papel e outros, assim como, com receitas da venda de recicláveis. Além desses benefícios econômicos, surgem alguns benefícios estratégicos, como melhoria na imagem institucional perante toda a sociedade, melhoria nas relações de trabalho entre a instituição e colaboradores e entre a sociedade, melhoria das relações com órgãos governamentais, comunidade e grupos ambientalistas, melhor adequação aos padrões ambientais, melhoria da criatividade para novos desafios de todos os envolvidos, entre outros.

De acordo com Bertoli e Ribeiro (2006, p. 120), durante o período em que ocorrer o investimento na gestão ambiental não haverá resultados imediatos, "mas, em períodos futuros, tais gastos possivelmente evitarão outros ainda maiores e de difícil mensuração, como multas e indenizações a terceiros, sem contar o benefício de se conseguir a proteção e preservação do meio ambiente ao invés da sua recuperação".

Portanto, como exposto, a gestão ambiental traz mais benefícios estratégicos à IES do que benefícios econômicos imediatos. É nesse sentido que os objetivos da implantação de um sistema de gestão ambiental devem ser elaborados e buscados, pois do contrário, objetivos voltados aos benefícios econômicos tendem a não serem atendidos.

\section{Metodologia}

O delineamento da pesquisa configura-se como um estudo exploratório, por meio da utilização de fontes secundárias e primárias, com abordagem dedutiva. $\mathrm{O}$ estudo exploratório, segundo Gil (1999), tem como principal objetivo esclarecer e modificar conceitos e idéias, com vistas na formulação de problemas mais precisos.

As fontes secundárias consubstanciam-se de pesquisa bibliográfica para a formação do referencial teórico, tendo como alvo livros e periódicos científicos. As fontes primárias foram coletadas em outubro de 2006, por meio de entrevistas com os três dirigentes principais da IES, que se contitui no estudo de caso.

A pesquisa compreende um estudo de caso centrado em uma única IES. Segundo Martins (2002), o estudo de caso dedica-se a estudos intensivos do passado, presente e interações ambientais de uma unidade social. A escolha da IES objeto de estudo foi intencional, motivada pela sua característica comunitária, filantrópica e regional.

Quanto aos procedimentos sistemáticos para formulação e aplicação da pesquisa, destaca-se que o instrumento selecionado consistiu de um roteiro de entrevista semiestruturado, com questões abertas, que foram debatidas juntamente com os três dirigentes principais da IES, num ambiente que preconizou predominante a abordagem qualitativa.

Richardson (1999) destaca que a abordagem qualitativa se caracteriza principalmente por não empregar instrumental estatístico na análise dos dados. A coleta de dados buscou investigar todos os pontos essenciais descritos nos objetivos do estudo para posterior descrição dos dados e a correspondente análise.

Os resultados da pesquisa limitam-se ao caso estudado, uma vez que se escolheu como estratégia de pesquisa estudar somente uma IES. Também está limitado às falas dos respondentes, que podem não ter se lembrado de abordar situações particulares relacionadas à gestão ambiental na IES. Portanto, não se realizou análise documental e nem mesmo utilizouse da técnica de observação. 


\section{Descrição dos resultados da pesquisa}

A IES pesquisada caracteriza-se como uma universidade comunitária, filantrópica e regional, com diversos campi distribuídos no Estado de Santa Catarina. No campus pesquisado possui aproximadamente 3.000 alunos matriculados em seus cursos de graduação. Também tem larga experiência na pós-graduação lato sensu, mas está engatinhando ainda no stricto sensu. A universidade foi constituída na década de 1990, a partir da unificação de três Fundações Educacionais existentes na região.

Para melhor entendimento dos resultados da pesquisa, vincularam-se as questões do questionário e as respectivas respostas aos objetivos específicos do presente estudo.

\subsection{Visão dos dirigentes sobre gestão ambiental na instituição de ensino superior}

No Quadro 1 apresentam-se as perguntas do roteiro de entrevista e as respectivas respostas dos dirigentes referente sua visão sobre gestão ambiental na IES.

\begin{tabular}{|c|c|}
\hline Perguntas do questionário & Respostas dos dirigentes \\
\hline $\begin{array}{l}\text { O Sistema de Gestão Ambiental (SGA) consiste } \\
\text { no planejamento e execução de atividades que } \\
\text { visam eliminação ou redução dos impactos ao } \\
\text { meio ambiente. Quais os sinalizadores de } \\
\text { iniciativas desta natureza na instituição de ensino } \\
\text { superior (IES) sob sua responsabilidade? }\end{array}$ & $\begin{array}{l}\text { Temos consciência de que os recursos da natureza, em sua } \\
\text { maioria, são renováveis, porém finitos. Nesse sentido, como } \\
\text { instituição de ensino, temos a obrigação de demonstrar nossa } \\
\text { consciência à sociedade, para que ela repense esse assunto e } \\
\text { faça sua parte instintivamente. }\end{array}$ \\
\hline $\begin{array}{l}\text { Quando os dirigentes da IES entenderam que era } \\
\text { o momento de iniciar a implantação de um } \\
\text { sistema de gestão ambiental na instituição? }\end{array}$ & $\begin{array}{l}\text { O quê nos despertou o interesse pelo gerenciamento } \\
\text { ambiental, foi o consumo expressivo de copos plásticos nos } \\
\text { bebedouros pelos alunos. Percebeu-se que grande parcela } \\
\text { desses não tem consciência do lixo que está produzindo. } \\
\text { Nesse caso, pensamos na reciclagem. Por outro lado, vemos } \\
\text { também a economia da matéria-prima. Percebemos também } \\
\text { que poderíamos aproveitar a água da chuva, visto que a } \\
\text { estrutura da universidade é grande, então, coletando essa } \\
\text { água, poderíamos aproveitá-la para os banheiros e calçadas. } \\
\text { Além desses, existem outros elementos reaproveitáveis, } \\
\text { como os papéis em geral, recipientes e outros. }\end{array}$ \\
\hline $\begin{array}{l}\text { Que fatores influenciaram suas crenças e valores } \\
\text { a respeito da necessidade de gerenciar a questão } \\
\text { ambiental em IES? }\end{array}$ & $\begin{array}{l}\text { As pessoas precisam estar conscientes das limitações do } \\
\text { meio ambiente e assumir com responsabilidade seu papel no } \\
\text { ambiente em que vivem. }\end{array}$ \\
\hline $\begin{array}{l}\text { Para o sucesso da gestão ambiental é necessário } \\
\text { o comprometimento de todos. Nesse sentido, } \\
\text { como a instituição envolveu e comprometeu seus } \\
\text { funcionários e dirigentes? }\end{array}$ & $\begin{array}{l}\text { Cada setor da universidade tem suas responsabilidades já } \\
\text { definidas. Dentro das já existentes, procuramos demonstrar a } \\
\text { cada um sua responsabilidade com o meio ambiente, através } \\
\text { da conscientização de se gerir adequadamente os poluentes } \\
\text { causados por cada um em particular. }\end{array}$ \\
\hline $\begin{array}{l}\text { Como envolveu e obteve o comprometimento } \\
\text { dos alunos da IES? }\end{array}$ & $\begin{array}{l}\text { Despertamos nos alunos a importância dos recursos naturais } \\
\text { para toda a humanidade. Assim, com a colaboração desses, } \\
\text { obter-se-ia na universidade uma quantia monetária pela } \\
\text { redução dos custos, sendo que essa quantia retornaria aos } \\
\text { alunos em forma de bolsas de estudo. }\end{array}$ \\
\hline $\begin{array}{l}\text { Quando da implantação de um SGA, toda a } \\
\text { hierarquia deve estar comprometida, visto que é } \\
\text { essencial para o seu êxito. Quais os } \\
\text { departamentos que julgam estarem diretamente } \\
\text { ligados ao sistema de gestão ambiental no } \\
\text { sentido de implementar e divulgar os objetivos } \\
\text { pretendidos? }\end{array}$ & $\begin{array}{l}\text { Em primeiro lugar, os dirigentes devem estar comprometidos } \\
\text { e diretamente ligados ao SGA. Depois, os coordenadores } \\
\text { juntamente com sua equipe de professores, visto que são } \\
\text { tidos pela maioria dos alunos como exemplos. Ainda, por } \\
\text { meio da contabilidade, é possível analisar economicamente } \\
\text { os resultados pretendidos e obtidos. Também o DCE deve } \\
\text { estar comprometido com os objetivos, pois representam os } \\
\text { interesses dos alunos. }\end{array}$ \\
\hline
\end{tabular}

Quadro 1 - Visão dos dirigentes sobre gestão ambiental na IES

Fonte: dados da pesquisa. 
Os recursos da natureza, em sua maioria, são renováveis, porém finitos. Nesse sentido, aproveitar a água da chuva para utilização nos banheiros e lavação das calçadas da IES significa poupar o potencial dos lençóis freáticos subterrâneos. Além disso, administrar o consumo da matéria-prima necessária à fabricação de bens é importante para a sustentabilidade das próximas gerações.

Percebe-se que grande parcela dos alunos e funcionários em geral não tem consciência da quantia de lixo produzida individualmente e dos danos causados à natureza. Em vista disso, acredita-se ser necessária a educação ambiental, iniciando pela conscientização da importância dos recursos do meio ambiente, seja em casa nos primeiros anos de vida ou na escola a partir das séries iniciais.

Considera-se baixo o nível de impacto na natureza das atividades da universidade. No entanto, já há iniciativas para diminuí-lo, pela condução de novos ordenamentos internos. Com relação à contabilidade, ela é peça fundamental nesse processo visto que informa os dirigentes sobre a situação financeira, econômica, patrimonial, sociail e ambiental, relacionada às atividades desenvolvidas pela instituição.

\subsection{Práticas e procedimentos de gestão ambiental adotados na IES}

No Quadro 2 apresentam-se as perguntas do roteiro de entrevista e as respostas dos dirigentes referentes às práticas e procedimentos de gestão ambiental adotados na IES.

\begin{tabular}{|c|c|}
\hline Perguntas do questionário & Respostas dos dirigentes \\
\hline $\begin{array}{l}\text { Quais ações podem ser arroladas como previstas } \\
\text { e executadas a partir do SGA desenvolvido na } \\
\text { IES? }\end{array}$ & $\begin{array}{l}\text { Conscientização dos recursos naturais; Responsabilidades } \\
\text { assumidas pelos dirigentes, professores e alunos na } \\
\text { sociedade, pela preservação do meio ambiente. }\end{array}$ \\
\hline $\begin{array}{l}\text { Que procedimentos denotam a preocupação e } \\
\text { movimentos em torno da gestão ambiental na } \\
\text { IES? }\end{array}$ & Sem resposta \\
\hline $\begin{array}{l}\text { A contabilidade tem como objetivo identificar, } \\
\text { mensurar e evidenciar nas demonstrações } \\
\text { contábeis e complementares, fatos pertinentes às } \\
\text { atividades da instituição. Nesse sentido, acredita } \\
\text { ser importante a contabilidade fornecer } \\
\text { informações relacionadas à gestão ambiental? }\end{array}$ & $\begin{array}{l}\text { Com certeza. A contabilidade é peça fundamental no sentido } \\
\text { de prover seus usuários de informações financeiras, } \\
\text { econômicas, patrimoniais e sociais, relacionadas às } \\
\text { atividades desenvolvidas pela instituição. }\end{array}$ \\
\hline $\begin{array}{l}\text { A contabilidade tem condições de evidenciar a } \\
\text { redução de custos com a implantação e execução } \\
\text { do SGA. A instituição planejou direcionar esse } \\
\text { montante para alguma área específica da } \\
\text { instituição ou algum projeto estratégico? }\end{array}$ & $\begin{array}{l}\text { Com a colaboração dos alunos, obteremos uma redução dos } \\
\text { custos, que retornará aos alunos sob forma de bolsas de } \\
\text { estudos. Além das bolsas, formaremos uma comissão } \\
\text { responsável pelo SGA interno da instituição, que também } \\
\text { será responsável para levar ao âmbito externo (escolas, } \\
\text { creches, asilos etc) a importância da consciência e } \\
\text { responsabilidade que todos têm dos recursos naturais. }\end{array}$ \\
\hline $\begin{array}{l}\text { Na IES são analisadas as variações entre as ações } \\
\text { previstas e realizadas no SGA? }\end{array}$ & $\begin{array}{l}\text { No momento, essas análises não são feitas com a devida } \\
\text { importância, visto que a comissão interna responsável, para } \\
\text { fazer essas análises dos objetivos pretendidos e realizados, } \\
\text { ainda não está formada. Entretanto, acompanhamentos estão } \\
\text { sendo feitos pelos dirigentes e contabilidade, sendo que } \\
\text { resultados positivos já foram verificados pela redução no } \\
\text { consumo de copos plásticos e pela separação espontânea do } \\
\text { lixo em lixeiros seletivos. }\end{array}$ \\
\hline $\begin{array}{l}\text { A contabilidade desta instituição elabora } \\
\text { anualmente o Balanço Social com informações } \\
\text { quantitativas e qualitativas em relação ao seu } \\
\text { desempenho social na comunidade em que está } \\
\text { inserida? }\end{array}$ & Sim \\
\hline
\end{tabular}

Quadro 2 - Práticas e procedimentos de gestão ambiental adotdos na IES

Fonte: dados da pesquisa. 
A partir do momento que a instituiçao decidiu implantar um SGA foi necessário evidenciar a importância dos recursos naturais aos alunos, funcionários e professores, pois os mesmos estão diretamente ligados aos objetivos da universidade, além de serem os principais responsáveis pelo sucesso ou não da implantação do SGA. Assim, pelo empenho de todos, na forma de redução de consumo de copos plásticos, economia de água, energia elétrica, papel e outros, obteve-se um benefício econômico.

Ainda, cada setor da universidade (contabilidade, compras, transporte, financeiro, etc) foi instigado a reconhecer suas responsabilidades com o meio ambiente, por meio da conscientização de se gerir adequadamente os poluentes causados por cada um em particular, dentro e fora da instituição. Ou seja, cada setor é responsável pela seleção dos materiais recicláveis por ele produzidos, como papel, plástico, revistas, jornais, etc.

No entanto, verificou-se a necessidade de formar uma comissão interna responsável pelo SGA, no sentido de fornecer, por meio de relatórios, as análises dos objetivos pretendidos e realizados. Essa comissão deve ser responsável pelo SGA interno da instituição, além de levar ao âmbito externo (escolas, creches, asilos etc) a importância da consciência e responsabilidade que todos têm dos recursos naturais. Pretende-se envolver as escolas municipais, estaduais e particulares dos municípios onde a instituição possui unidades.

\subsection{Benefícios sociais e estratégicos da gestão ambiental percebidos na IES}

No Quadro 3 apresentam-se as perguntas do roteiro de entrevista e respectivas respostas dos dirigentes referentes aos benefícios sociais e estratégicos da gestão ambiental percebidos na IES.

\begin{tabular}{|c|c|}
\hline Perguntas do questionário & Respostas dos dirigentes \\
\hline $\begin{array}{l}\text { A implantação de um SGA não é obrigatória por } \\
\text { lei. Como a instituição visualiza seu } \\
\text { posicionamento na sociedade, no sentido de } \\
\text { assumir sua responsabilidade social? }\end{array}$ & $\begin{array}{l}\text { A responsabilidade social é um compromisso da instituição } \\
\text { com a sociedade, principalmente pela sua característica: } \\
\text { comunitária, filantrópica e educadora. A instituição } \\
\text { promove a responsabilidade também pela implantação de } \\
\text { cursos tecnológicos e especialização em gestão ambiental. }\end{array}$ \\
\hline $\begin{array}{l}\text { Como se posiciona, estando a frente de outras } \\
\text { instituições, que pela particularidade de suas } \\
\text { atividades, deveriam conscientizar-se da } \\
\text { responsabilidade social e ambiental, mas no } \\
\text { entanto, não o fazem? }\end{array}$ & A instituição está cumprindo com sua missão. \\
\hline $\begin{array}{l}\text { A Responsabilidade Social é questionada ou } \\
\text { exigida por algum órgão ou instituição quando da } \\
\text { liberação ou contratação de recursos financeiros? }\end{array}$ & $\begin{array}{l}\text { Sim. Pelo fato da instituição ser filantrópica e comunitária, } \\
\text { o BNDES exige a apresentação do Balanço Social com } \\
\text { informações quantitativas e qualitativas em relação ao } \\
\text { desempenho social na comunidade. }\end{array}$ \\
\hline $\begin{array}{l}\text { Acredita ser viável implantar um sistema de } \\
\text { gestão ambiental em parceria com outros órgãos } \\
\text { públicos ou privados, objetivando a educação } \\
\text { ambiental de toda a comunidade? } \\
\text { Quais são os benefícios sociais e estratégicos } \\
\text { percebidos com as ações decorrentes da } \\
\text { implantação do SGA na IES? } \\
\text { Quais são as desvantagens percebidas com as } \\
\text { ações decorrentes da implantação do SGA na IES? } \\
\text { Que medidas são necessárias para melhorar o } \\
\text { SGA implantado? }\end{array}$ & $\begin{array}{l}\text { Estamos desenvolvendo um projeto com o objetivo de } \\
\text { conscientizar cada um de sua cota de responsabilidades } \\
\text { para com o meio ambiente. Esse projeto pretende envolver } \\
\text { as escolas municipais, estaduais e particulares dos } \\
\text { municípios onde a instituição têm unidades. } \\
\text { Maior conscientização dos alunos, funcionários e } \\
\text { professores da instituição na preservação dos recursos } \\
\text { naturais. } \\
\text { Consideramos que todas as ações são voltadas ao benefício } \\
\text { da instituição e sociedade. } \\
\text { Sem resposta }\end{array}$ \\
\hline
\end{tabular}

Quadro 3 - Benefícios sociais e estratégicos da gestão ambiental percebidos na IES

Fonte: dados da pesquisa. 
Destaca-se que a comunidade e o meio ambiente auferem benefícios sociais quando a população passa a ter consciência dos recursos naturais e maior conhecimento das limitações ambientais, especialmente quando assume sua responsabilidade com a preservação do meio ambiente. Também ganham quando há um comprometimento das organizações pelo destino correto do lixo produzido, reciclável ou não.

Por outro lado, o comprometimento da instituição em destinar corretamente o lixo produzido, sem obrigatoriedade por lei, mas pela responsabilidade com o meio ambiente, implica um benefício estratégico, visto que a sociedade passa a considerá-la uma instituição ambientalmente correta. Nesse sentido, observa-se uma melhoria nas relações de trabalho entre a instituição e os colaboradores, estimulando-os a novos desafios.

Pelo fato da instituição ser filantrópica e comunitária, elabora anualmente o Balanço Social com informações quantitativas e qualitativas das ações promovidas em torno da responsabilidade social. A partir daí surgem alguns benefícios estratégicos, como a melhoria das relações com os órgãos governamentais, comunidade e grupos ambientalistas, assim como uma melhor adequação aos padrões ambientais.

\section{Conclusões}

O estudo objetivou descrever a gestão ambiental em Instituição de Ensino Superior comunitária, na visão de seus dirigentes. Para tanto, realizou-se pesquisa explortória, por meio de estudo de caso em uma Instituição de Ensino Superior filantrópica e comunitária, com abordagem qualitativa dos dados coletados em entrevista com os dirigentes.

$\mathrm{Na}$ visão dos dirigentes entrevistados, a gestão ambiental em IES tende a criar benefícios ao meio ambiente e à própria instituição. $\mathrm{O}$ meio ambiente ganha quando existe uma racionalidade no uso dos recursos naturais, como por exemplo, o uso racional da água. Também ganha, quando deixa de receber poluentes oriundos das atividades operacionais da instituição, como esgoto, recipientes, papel, plástico, vidro, etc.

Para a IES pesquisada, a gestão ambiental lhe beneficia com a economia de custos pela redução do consumo de água, energia elétrica, papel e outros, além de gerar receitas com a venda de recicláveis. A redução de custos pode se refletir na redução do valor das mensalidades dos alunos, proporcionando possibilidades de ampliação da receita total com maior número de matrículas nos diferentes cursos oferecidos.

Além desses benefícios econômicos, foram constatados alguns benefícios estratégicos, como melhoria na imagem institucional perante toda a sociedade, melhoria nas relações de trabalho entre a instituição e colaboradores. Além disso, melhoria das relações com órgãos governamentais, comunidade e grupos ambientalistas, melhor adequação aos padrões ambientais, melhoria da criatividade para novos desafios de todos os envolvidos, entre outros.

Conclui-se que a gestão ambiental traz benefícios para o meio ambiente, pela redução ou eliminação de poluentes, bem como par a própria instituição, seja como economia de custos ou aumento da receita total, além de benefícios estratégicos à IES. É nesse sentido que os objetivos da implantação de um sistema de gestão ambiental devem ser elaborados e buscados, pois do contrário, objetivos voltados aos benefícios econômicos tendem a não serem atendidos.

Os resultados da pesquisa provocam inquietações que podem ser objeto de novas pesquisas sobre o tema investigado. A gestão ambiental verificada nesta IES se reproduz em Instituições de Ensino Superior congêneres? Qual a relevância dos elementos intangíveis na gestão ambiental em IES desta natureza? Como mensurar a satisfação dos envolvidos nas questões de responsabilidade social da IES estudada? Estas são algumas das questões que podem ser formuladas com base na pesquisa realizada. 


\section{Referências}

ASSOCIAÇÃO BRASILEIRA DE NORMAS TÉCNICAS. 1996. Sistema de gestão ambiental: especificação e diretrizes para uso. NBR ISO 14000. Rio de Janeiro, out.

BERTOLI, A.L. e RIBEIRO, M.S. 2006. Passivo ambiental: esudo de caso da Petróleo Brasileiro S.A. - Petrobrás. A recuparação ambiental nas demonstrações contábeis, em conseqüência dos acidents ocorridos. Revista de Administração Contemporânea - RAC, v. 10, n. 2, p. 117-136, abr./jun.

CALIXTO, L., BARBOSA, R.R. e LIMA, M.B. 2007. Disseminação de informações ambienais voluntárias: relatórios contábeis versus internet. Revista Contabilidade \& Finaças - USP, v. 18, Edição 30 anos de dutorado, p. 84-95, jun.

FERREIRA, A.C. S. 2003. Contabilidade Ambiental. São Paulo: Atlas.

GIL, A.C. 2002. Como elaborar projetos de pesquisa. 4. ed. São Paulo: Atlas.

INSTITUTO ETHOS DE RESPONSABILIDADE SOCIAL. Disponível em: $<$ http://www.ethos.org.br>. Acesso em: 08 maio 2006.

ISO. 1998. Development manual: enviromental management and ISO 14000. ISO: Geneve.

LEONARDO, V.S. 2006. Um estudo sobre gastos ambientais presentes na contabilidade de indústrias químicas brasileiras. Contabilidade Vista \& Revista, v. 17, n. 2, p. 89-109, abr./jun.

MARTINS, G.A. 2002. Manual para elaboração de monografias e dissertações. 3. ed. São Paulo: Atlas.

OLIVEIRA, F.R.M. 2002. Relações públicas e a comunidade na empresa cidadã. In: Vários autores. Responsabilidade Social das empresas: a contribuição das universidades. São Paulo.

PEREIRA, C.A. 1999. Ambiente, empresa, gestão e eficácia. In: CATELLI, A. (org.) Controladoria: uma abordagem da gestão econômica - GECON. São Paulo: Atlas. p.35-80.

REHFELDT, K.H. 2006. Eu gosto de mim. Blumenau: Odorizzi.

RICHARDSON, R.J. 1999. Pesquisa social: métodos e técnicas. 3. ed. São Paulo: Atlas.

RIBEIRO, M.S. 2006. Contabilidade ambiental. São Paulo: Saraiva.

ROSINI, A.M. e PALMISANO, A. 2003. Administração de sistemas de informação e a gestão do conhecimento. São Paulo: Thomson.

TINOCO, J.E.P. e KRAEMER, M.E.P. 2004. Contabilidade e gestão ambiental. São Paulo: Atlas. 